\title{
Light Load Efficiency Improvement in Variable DC-link Voltage Inverter Systems for Home Appliances
}

\author{
Hyun Soo Park*, Minkook Kim* and Byoung Kuk Lee ${ }^{\dagger}$
}

\begin{abstract}
This paper describes an efficiency improvement scheme in variable dc-link voltage inverter systems for home appliances and especially focuses on the light load operating area. Although, variable dc-link voltage according to the load could improve the efficiency of inverter, it can cause complex operation and low efficiency of PFC circuit. Therefore, in this paper buck boost selective control scheme is proposed to increase the efficiency of PFC circuit under low dc-link voltage. The validity of the proposed scheme is verified by $2.2 \mathrm{~kW}$ dynamo system and maximum $6.5 \%$ system efficiency improvement could be achieved.
\end{abstract}

Keywords: Buck boost selective control, Light load efficiency, Power factor correction, Variable dclink

\section{Introduction}

As power consumption by homes and buildings increases, it is increasingly important to have high-efficiency home appliances, such as air-conditioners and refrigerators. Fig. 1 shows variations in the annual operation time, power consumption, and efficiency of air-conditioners according to the load conditions. As shown in Fig. 1, compared to heavy loads, the duration of power consumption under light loads increases and the efficiency of the inverter compressor gradually decreases. Therefore, it can be noted that in order to decrease the overall power consumption, improvement of the efficiency at light loads is very important because it makes up a large portion of the overall power consumption. A major factor in the efficiency degradation under light loads is the high input voltage with the low back electromotive force (back-EMF) of the driving motor, which lead to very large conduction losses. On the other hand, under heavy loads, the field weakening control to obtain the maximum torque with a given voltage limit degrades the system efficiency.

Several kinds of approaches are proposed to overcome these problems. The PWM (Pulse Width Modulation) frequency changing method changes the frequency depending on the load conditions to reduce switching losses; however, the transient state has side effects on THD (Total Harmonic Distortion) and power factor [1]. The nonlinear inductor uses dc bias characteristics in inverse proportion to the inductor current [2]. This method reduces ripples and iron losses by material characteristics, though an additional nonlinear inductor increases conduction losses. Phase shedding uses at least two converters and

$\uparrow$ Corresponding Author: Department of Electrical and Computer Engineering, Sungkyunkawn Univ., Korea. (bkleeskku@skku.edu)

* Department of Electrical and Computer Engineering, Sungkyunkawn Univ., Korea (greenbee@skku.edu)

Received: June 3, 2016; Accepted: July 18, 2016 operates only one of them under light loads to improve system efficiency [3]. However, no less than a pair of converters should be used. Changing the dc-link voltage reduces the conduction losses of inverter in the condition of the back-EMF [4]. In order to change the dc-link voltage, a PFC (Power Factor Correction) circuit could be utilized, which can make the hardware complicated and the efficiency of the PFC should be considered.

In this paper, efficiency improvement under light loads is discussed with dc-link voltage variation considering the efficiency of the inverter and the PFC simultaneously. PFC operation is also discussed because PFC provides a dc-link voltage to improve the efficiency under light loads. In detail, a combination of buck-boost selective control and phase shedding control is used. Moreover, an optimal operation method for dc-link voltage and PFC control is proposed to obtain the minimum power consumption for optimal system efficiency.
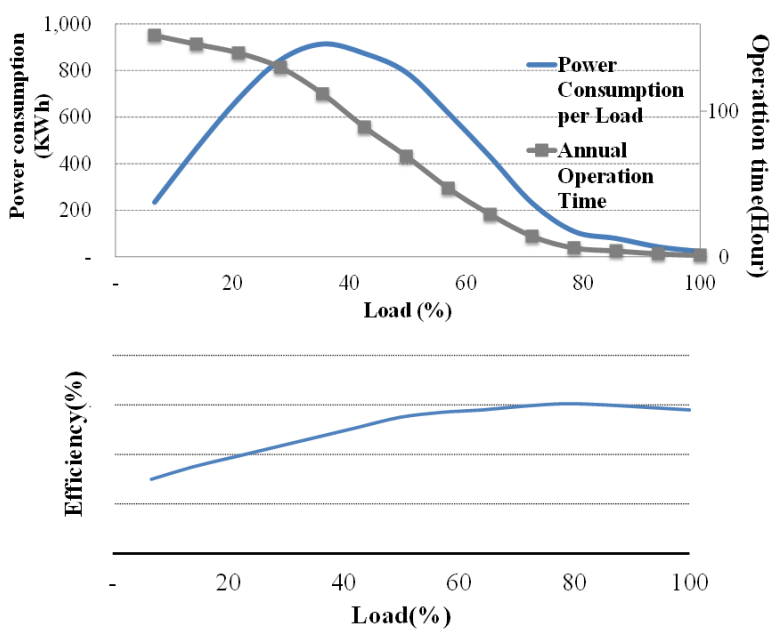

Fig. 1. Typical example of air-conditioner compressor system load characteristics. 


\section{Variable DC-link Voltage Inverter System}

Home appliances operated at a current lower than $16 \mathrm{~A}$, such as air-conditioners, should satisfy harmonic standard IEC 61000-3-2 [5]. Therefore, a PFC circuit is usually used to reduce the harmonic component. Moreover, the PFC circuit also controls the power factor and dc-link voltage.

In general, for an inverter compressor system as shown in Fig. 2, the dc-link voltage is not changed by the PFC control. This type of constant dc-link voltage inverter maintains the same voltage level even under a light load that has the low voltage level of the back-EMF. Conduction losses from inverters are relatively large owing to the high voltage difference between the dc-link and the back-EMF. Moreover, the voltage of the back-EMF under a heavy load is almost the same as or slightly lower than the dc-link voltage. In this case, to increase the speed of the motor, a special and complex control method should be used, for example field weakening control. Field weakening control should use the d-axis current, which leads to additional losses from the inverter.

A variable dc-link voltage system is one solution to overcome the problems of constant dc-link voltage inverters and to achieve high efficiency under light loads [6].

In detail, the total loss from a six-switch inverter is the sum of conduction losses and switching losses, as expressed by (1).

$$
\begin{aligned}
& P_{\text {conduct }}=\sum_{n=1}^{6}\left[\int_{0}^{T} V_{n c e}(t) \times I_{n c e}(t)\right] d t \\
& P_{s w}=\sum_{n=1}^{6} F_{s w_{-} n} \times \frac{E_{s w_{-} n}(\text { on })+E_{s w_{-} n}(\text { off })}{\pi} \\
& P_{\text {total }}=P_{\text {conduct }}+P_{s w}
\end{aligned}
$$

where $P_{\text {conduct }}$ is the conduction losses from the inverter, $P_{s w}$ is the switching losses from the inverter, $V_{n c e}$ is the n-th IGBT (Insulated Gate Bipolar Transistor) collector emitter voltage, $I_{n c e}$ is the n-th IGBT collector emitter current, $F_{s w-n}$ is the switching frequency of the n-th IGBT, $E_{s w_{n} n}$ is the energy dissipations of the n-th IGBT, and $P_{\text {total }}$ is the total power consumption.

The back-EMF is small with light loads, which gives a large voltage to switch. Therefore, $E_{s w n}(o n)$ and $E_{s w n}(o f f)$

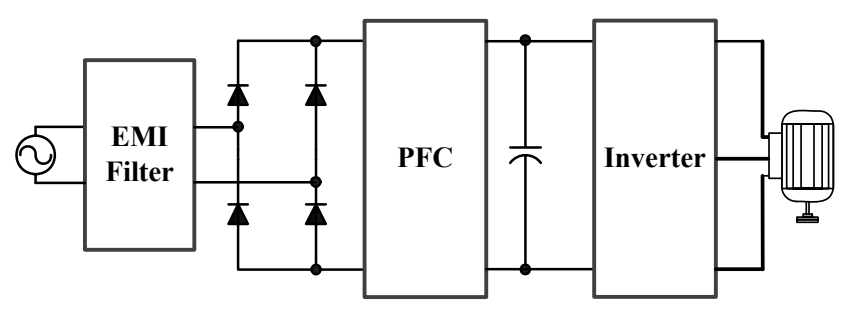

Fig. 2. System block diagram of inverter compressor.

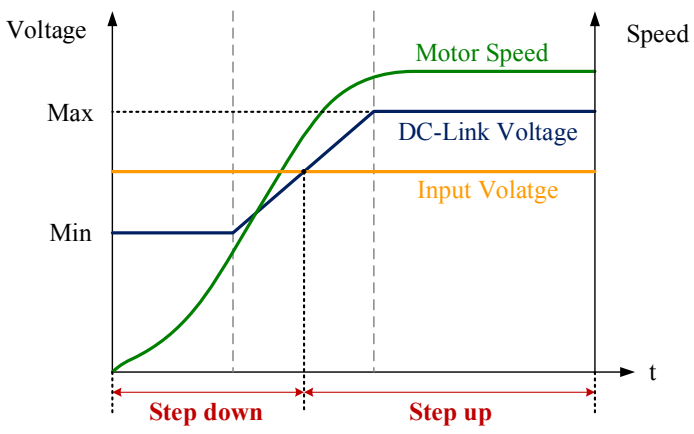

Fig. 3. Control concept of variable dc-link voltage inverter system with variation in motor speed.

from voltage changes are relatively large. In this case, the low dc-link voltage decreases the switching losses from the inverter. On the contrary, the back-EMF is large with a heavy load, which leads to small switching losses from voltage changes. In this case, variation in the dc-link voltage is effective for reducing the switching losses, while conduction losses from the inverter are almost constant with the variance of the dc-link voltage because $V_{n c e}$ is almost constant.

Fig. 3 shows the control concept of the variable dc-link voltage inverter system. This system changes the dc-link voltage according to the speed of the motor. The voltage of the dc-link is high at high speed and low at low speed because the motor speed has a somewhat directly proportional relation to load.

It is essential to consider various kinds of conditions to change the dc-link voltage, for example the back-EMF, the voltage limitation of switch, the ripple current, and so on. According to these conditions, some limitation of the dclink voltage range is needed. The low limit for the dc-link voltage should be set by the efficiency of the PFC circuit and minimum voltage needed to operate the motor. The high limit for the dc-link voltage should be set by the maximum speed of the motor, the efficiency of PFC the circuit, the voltage limitation of the switch, and the internal voltage limitation of the capacitor. Considering various conditions, the low limit for the dc-link voltage was selected as $270 \mathrm{~V}$ to satisfy the operation of the motor and the torque limitation of the compressor. The high limit of the dc-link voltage was selected as $400 \mathrm{~V}$ to satisfy the internal voltage limitation of the capacitor.

The grid voltage condition has a range of $220-230 \mathrm{~V}$. The peak voltage range after rectifying is from 311 to 325 V. Not only step-up but also step-down functions should be realized to change the rectified voltage to the range of 270 $400 \mathrm{~V}$. In order to obtain this range of voltage, both buck and boost operation should be performed. Cascade buckboost PFC is one of the most suitable topologies to consider the power density and rating voltage of the capacitor [7]. This paper proposes reducing losses in cascade buck-boost PFC. Fig. 4 shows the block diagram of the variable dc-link voltage inverter system. 


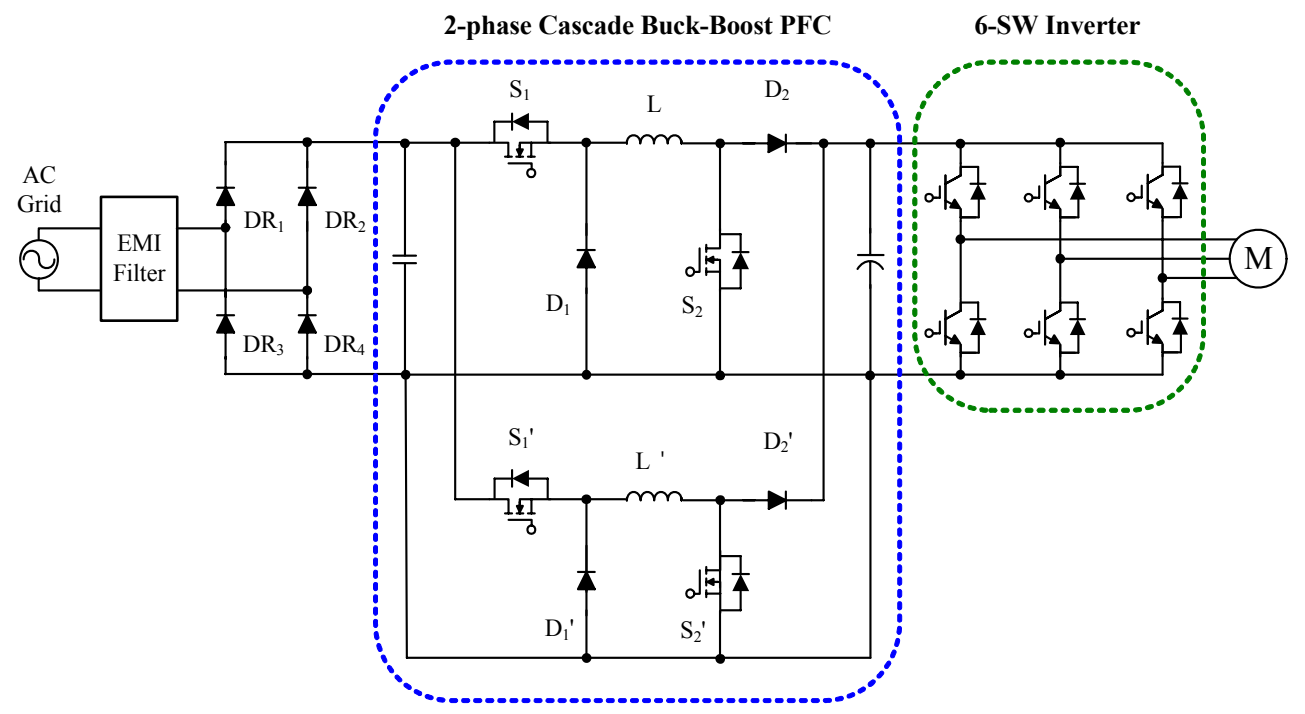

Fig. 4. Variable dc-link voltage inverter system blocks.

\section{Proposed Buck-boost Selective and Phase Shedding Control Algorithm}

Two kinds of algorithms to improve the efficiency in variable dc-link voltage inverter systems are presented. One is buck-boost selective control and the other is phase shedding control. These two algorithms are merged to achieve high efficiency at the PFC part.

With buck-boost synchronous control, it is possible to do step-up and step-down functions regardless of the load status. The algorithm for the control is simple and always the same for step-up or step-down. The same control signals are used for operating the step-up and step-sown switches.

However, buck-boost synchronous control can deteriorate the efficiency because both switches are operated at the same time. If one of the switches is operated for step-up or step-down, switching losses can be reduced. Buck-boost selective control is one solution to improve efficiency. Fig. 5 shows the PWM waveform of buck-boost synchronous control and buck-boost selective control.

Buck-boost selective control selects buck or boost control by comparing the input voltage and the dc-link voltage. According to the selection results, only one switch is fully on or off, which is why the losses with buck-boost selective control are less than those with buck-boost synchronous control [8].

Buck-boost selective control also has the benefit of a power factor and THD because the input current is continuous in boost control.

The loss with buck-boost synchronous control $P_{\text {buck_boost_sync }}$ is expressed in (2).

$$
\begin{aligned}
& P_{\text {buck_boost_sync }}=P_{\text {s1sync }}+P_{\text {s2sync }} \\
& =P_{\text {s1sync_cond }}+P_{\text {s1sync_sw }}+P_{s 2 s y n c \_c o n d}+P_{\text {s2sync_sw }}
\end{aligned}
$$

where $P_{\text {slsync }}$ is the loss of $\mathrm{S}_{1}, P_{\text {s2sync }}$ is the loss of $\mathrm{S}_{2}$, $P_{\text {sIsync cond }}$ is the conduction loss of $\mathrm{S}_{1}, P_{\text {slsync sw }}$ is the switching loss of $\mathrm{S}_{1}, P_{\text {s2sync cond }}$ is the conduction loss of $\mathrm{S}_{2}$, and $P_{\text {s2sync sw }}$ is the switching loss of $\mathrm{S}_{2}$. Switches $\mathrm{S}_{1}$ and $\mathrm{S}_{2}$ operate at the same time. In this case, switching losses are larger than with only one switch operating.

The loss with buck-boost selective control $P_{\text {buck_boost_selective }}$ is expressed in (3).

$$
\begin{aligned}
& P_{\text {buck_boost_selective }}=P_{\text {boost }}+P_{\text {buck }}
\end{aligned}
$$

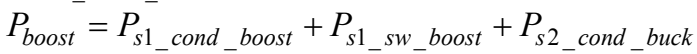

$$
\begin{aligned}
& P_{\text {buck }}=P_{s 2_{-} \text {cond_buck }}+P_{s 2_{-} s w_{-} \text {buck }}
\end{aligned}
$$

where $P_{\text {boost }}$ is the loss of boost control, $P_{\text {buck }}$ is the loss of buck control, $P_{s 1 \_c o n d \_b o o s t}$ is the conduction loss of $\mathrm{S}_{1}$, $P_{s 1 \text { sw boost }}$ is the switching loss of $\mathrm{S}_{1}, P_{s 2}$ cond buck is the conduction loss of $\mathrm{S}_{2}$, and $P_{s 2 \text { sw buck }}$ is the switching loss of $\mathrm{S}_{2}$. These losses are shown in Fig. 5(b).

In the case of buck-boost selective control, only one switch is operated so the power consumption of buckboost selective control is less than that of buck-boost synchronous control. Table 1 shows the switch operation and detailed losses for each control.

Fig. 6 shows a control block diagram of the two-phase buck-boost selective control. The basic control scheme for buck-boost selective control comes from the voltage

Table 1. Switch operation for each control

\begin{tabular}{c|c|c|c|c} 
& \multicolumn{2}{c|}{ (S : Switching losses, C : Conduction losses) } \\
\hline & \multicolumn{2}{|c|}{ Boost case } & \multicolumn{2}{c}{ Buck case } \\
\hline & $\begin{array}{c}\text { Switch } \\
\text { operation }\end{array}$ & Losses & $\begin{array}{c}\text { Switch } \\
\text { operation }\end{array}$ & Losses \\
\hline Buck-boost & $\mathrm{S}_{1}:$ on/off & $\mathrm{S} / \mathrm{C}$ & $\mathrm{S}_{1}:$ on/off & $\mathrm{S} / \mathrm{C}$ \\
Synchronous Control & $\mathrm{S}_{2}:$ on/off & $\mathrm{S} / \mathrm{C}$ & $\mathrm{S}_{2}:$ on/off & $\mathrm{S} / \mathrm{C}$ \\
\hline Buck-boost Selective & $\mathrm{S}_{1}:$ on & $\mathrm{C}$ & $\mathrm{S}_{1}:$ on $/$ off & $\mathrm{S} / \mathrm{C}$ \\
Control & $\mathrm{S}_{2}:$ on/off & $\mathrm{S} / \mathrm{C}$ & $\mathrm{S}_{2}:$ off & - \\
\hline
\end{tabular}




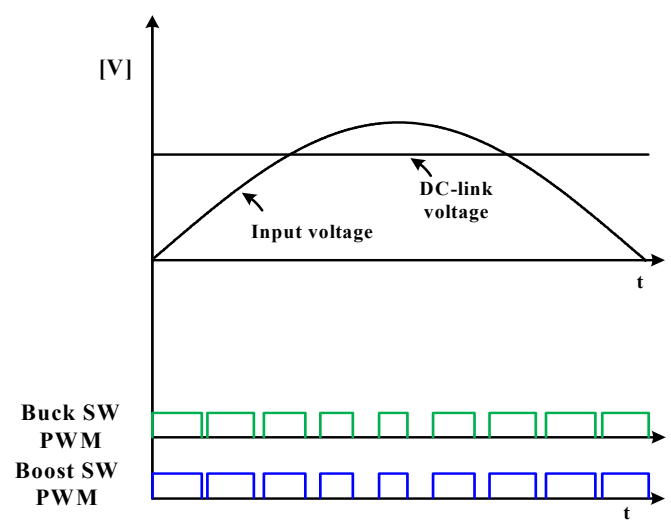

(a) Buck-boost synchronous control

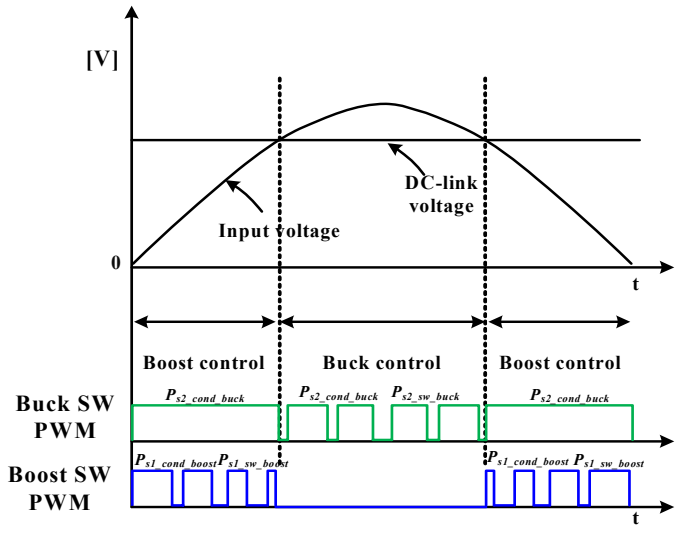

(b)Buck-boost selective control

Fig. 5. PWM waveform of buck-boost synchronouscontrol and buck-boost selective control.

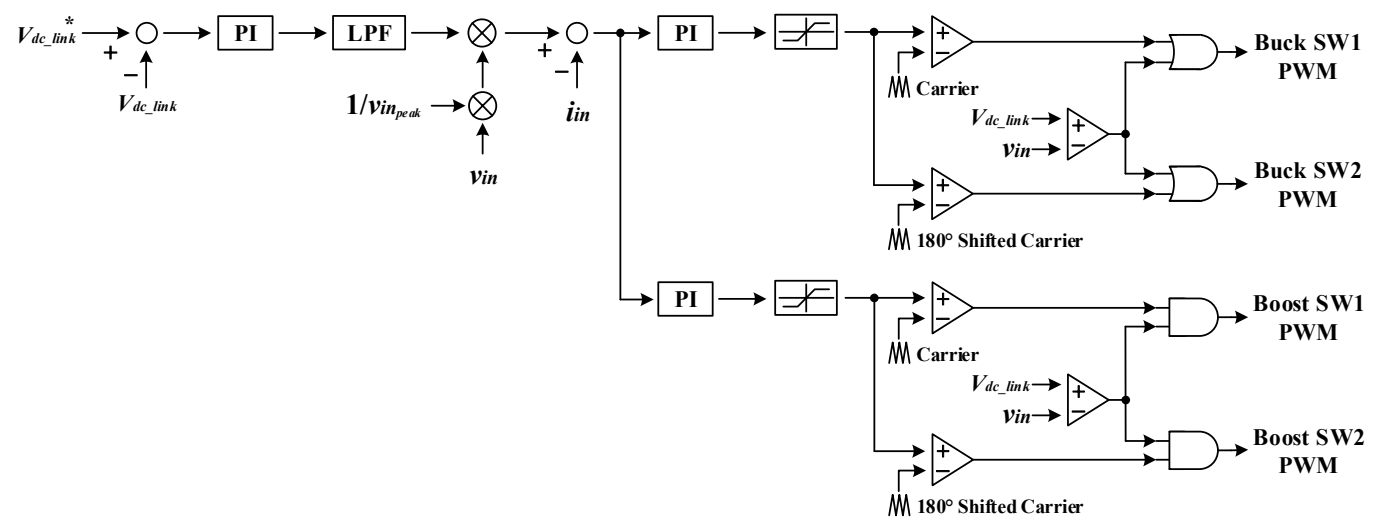

Fig. 6. PFC control block for the buck-boost selective control

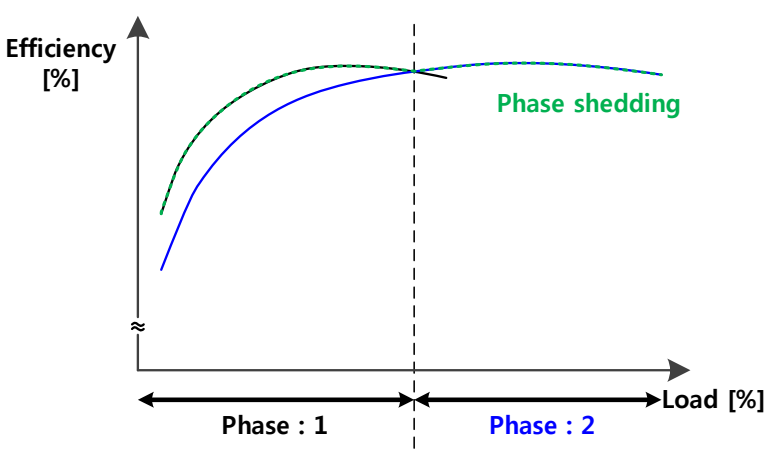

Fig. 7. Comparison of effects of phase shedding and normal control.

difference between the target and the reference. The final control step to select buck switch or boost switch is important. Output comparison between the controlled voltage and the dc-link voltage selects buck control or boost control in buck-boost selective control. The output PWM control signal controls $\mathrm{S}_{1}$ and $\mathrm{S}_{2}$. Power factor was more than 0.99 in simulation all kinds of loads.

Phase shedding control uses single phase with light loads and multi-phase (interleaving) operation with heavy loads. With light loads, phase shedding has the benefit of reducing switching and reversing recovery losses. Phase shedding control also reduces the individual inductor capacity. It has the benefit of minimizing inductor losses [3].

Fig. 7 shows the efficiency graph for phase shedding and normal operation.

\section{Experimental Verification}

In order to verify the proposed topology and control algorithms, experiments were performed with the $2.2-\mathrm{kW}$ prototype of the system parameters in Table 2. Fig. 8 shows the test-bed for the experiment. Load variation was performed by the test-bed and the dynamo system.

The integrated PFC efficiency experiment was carried out with three kinds of conditions.

The first condition is variation of the dc-link voltage. The range of the dc-link voltage is from $270 \mathrm{~V}$ to $400 \mathrm{~V}$. The second condition is the control method for the PFC. One is buck-boost selective control and the other is buckboost synchronous control. The third condition is phase 
Table 2. Experiment parameters

\begin{tabular}{c|l|l}
\hline & \multicolumn{1}{|c|}{ Parameter } & \multicolumn{1}{c}{ Value [Unit] } \\
\hline \multirow{4}{*}{ PFC } & Input Voltage & $220[$ Vac] \\
\cline { 2 - 3 } & Input Frequency & $60[\mathrm{~Hz}]$ \\
\cline { 2 - 3 } & Input Current (@ 220 Vac) & $10.5[\mathrm{Arms}]$ \\
\cline { 2 - 3 } & Maximum Input Power & $2.27[\mathrm{~kW}]$ \\
\cline { 2 - 3 } & Power Factor & $0.98 @[\mathrm{~kW}]$ \\
\hline \multirow{2}{*}{ Inverter } & Dc-link Voltage & $270-400[\mathrm{~V}]$ \\
\cline { 2 - 3 } & Maximum Power & $2.2[\mathrm{~kW}]$ \\
\hline \multirow{2}{*}{ Motor } & RPM & $200 \sim 3000[\mathrm{RPM}]$ \\
\cline { 2 - 3 } & Torque & $1.9 \sim 5.6[\mathrm{Nm}]$ \\
\hline
\end{tabular}

Table 3. Control difference between the reference condition and the proposed condition

\begin{tabular}{c|c|c}
\hline & Reference condition & Proposed condition \\
\hline Dc-link voltage & $380 \mathrm{~V}$ & $270-400 \mathrm{~V}$ \\
\hline PFC method & $\begin{array}{c}\text { Buck-boost synchronous } \\
\text { control }\end{array}$ & $\begin{array}{c}\text { Buck-boost selective } \\
\text { control }\end{array}$ \\
\hline Phase shedding & One phase & One or two phase \\
\hline
\end{tabular}

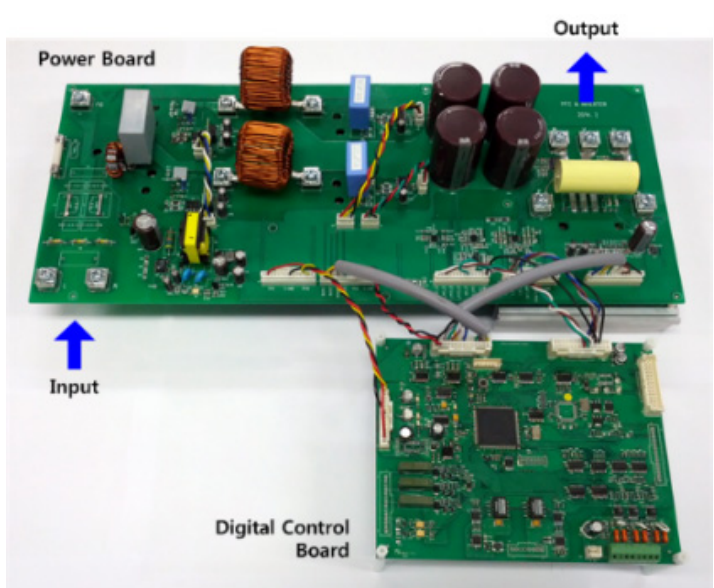

Fig. 8. Test-bed for variable dc-link voltage inverter system.

shedding control. Single-phase control and two-phase (non-phase shedding, multi-phase, interleaving) control were tested in the experiment. In the case of single phase, the total acceptable power is half of the maximum. The PWM frequency of PFC is $50 \mathrm{KHz}$. The control difference between the reference system and the proposed system is expressed in Table 3.

According to the input power, these control conditions should be changed. This proposed strategy is expressed in (4).

$$
\left[\begin{array}{c}
f_{D C_{-} \text {link }}(p) \\
f_{\text {PFC }}(p) \\
f_{\text {Phase }}(p)
\end{array}\right]=\left[\begin{array}{c}
270 \quad V \\
\min (\text { buck_boost_selective,buck_boost_sync }) \\
\min (1 \text { phase, } 2 \text { phase })
\end{array}\right]
$$

where $p$ is the input power, $f_{D C_{-} \text {link }}(p)$ is the optimal voltage

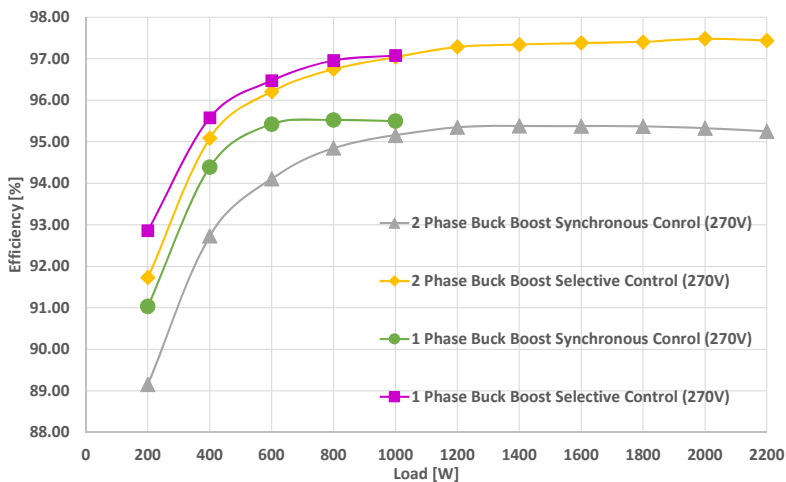

Fig. 9. Experimental efficiency comparison between buckboost selective control and phase shedding with fixed dc-link voltage.

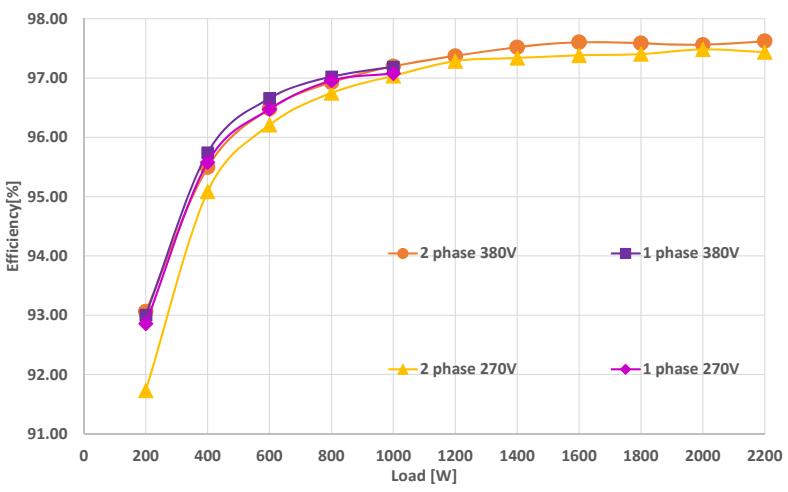

Fig. 10. Experimental efficiency comparison between variable dc-link voltage and phase shedding with buck-boost selective control.

of the dc-link, $f_{P F C}(p)$ is the optimal selection between buck-boost selective control and buck-boost synchronous control to obtain the minimum power consumption, and $f_{\text {Phase }}(p)$ is the optimal selection of phase shedding control to obtain minimum power consumption.

The second and third conditions select the values for the control method. On the other hand, the first condition is the optimal voltage value to achieve the minimum power consumption, which is relatively hard to obtain. Thus, with some fixed dc-link voltage condition, the second and third conditions are changed to observe the efficiency variation.

Fig. 9 shows the experimental efficiency of buck-boost selective control and phase shedding with a $270 \mathrm{~V}$ dc-link voltage. Buck-boost selective control always has 1-2.5\% better performance compared to that of buck-boost synchronous control. In the case of the second condition, buck-boost selective control is the solution to minimizing the power consumption. Phase shedding has $1-2 \%$ better performance compared to that of two-phase control. It can be used for half load conditions.

In case of dc-link voltage, $270 \mathrm{~V}$ and $380 \mathrm{~V}$ are used to check the efficiency tendency. Fig. 10 shows the experimental efficiency of the variable dc-link voltage and 


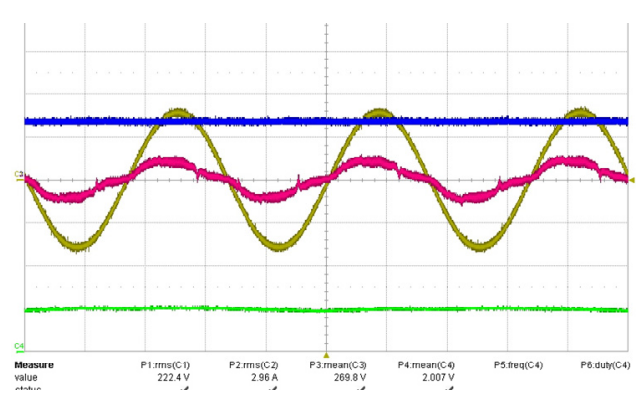

(a) one phase $600 \mathrm{~W}$

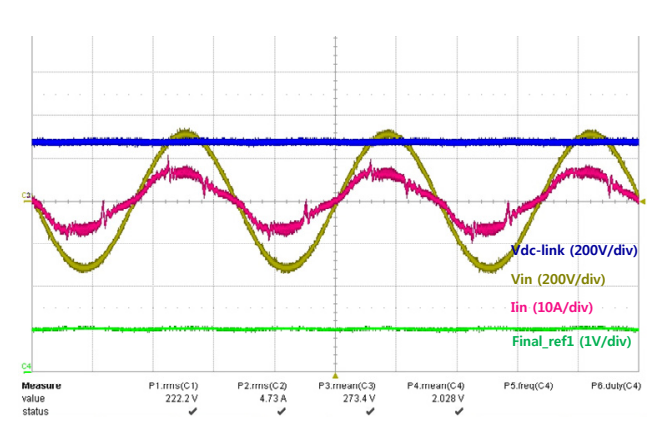

(b) two phase $1200 \mathrm{~W}$

Fig. 11. Experimental waveform between one phase $600 \mathrm{~W}$ and two phase $1200 \mathrm{~W}$.

phase shedding. As buck-boost selective control was found to be effective, it is used commonly. $380 \mathrm{~V}$ dc-link voltage has good performance compared to that achieved with 270 $\mathrm{V}$ in PFC efficiency. This voltage affects not only the PFC efficiency but also the inverter efficiency. System performance should be determined by simultaneously considering the PFC and the inverter.

Fig. 11 shows operation waveform of proposed system in case dc-link voltage is $270 \mathrm{~V}$. Phase difference between input voltage and input current is almost zero regardless of phase shedding control. During the experiment, power factor was more than 0.98 from $200 \mathrm{~W}$ to $2200 \mathrm{~W}$. That means PFC operated correctly.

According to the PFC efficiency experimental results, buck-boost selective control is used commonly, and onephase is used below $1100 \mathrm{~W}$, which is half of the maximum power in the PFC and inverter integration test. These conditions for the PFC and inverter integration test are expressed in Eq. (5).

$$
\left[\begin{array}{c}
f_{D C_{-} \text {link }}(p) \\
f_{\text {Phase }}(p)
\end{array}\right]=\left[\begin{array}{c}
270 \mathrm{~V} \sim 400 \mathrm{~V} \\
p>1100 \mathrm{~W}: 2 \text { phase } \\
p \leq 1100 \mathrm{~W}: 1 \text { phase }
\end{array}\right]
$$

The total system efficiency can be calculated from multiplication of the PFC part and the inverter part. In the real situation, there are several factors to consider. For
Table 4. Control strategy for optimal efficiency

\begin{tabular}{c|c|c}
\hline Section & Dc-link voltage & Phase shedding \\
\hline $0-500 \mathrm{~W}$ & $270 \mathrm{~V}$ & One phase \\
\hline $500-1100 \mathrm{~W}$ & $300 \mathrm{~V}$ & One phase \\
\hline $1100-1500 \mathrm{~W}$ & $330 \mathrm{~V}$ & Two phase \\
\hline $1500-2100 \mathrm{~W}$ & $380 \mathrm{~V}$ & Two phase \\
\hline $2100 \mathrm{~W} \sim$ & $400 \mathrm{~V}$ & 2 phase \\
\hline
\end{tabular}

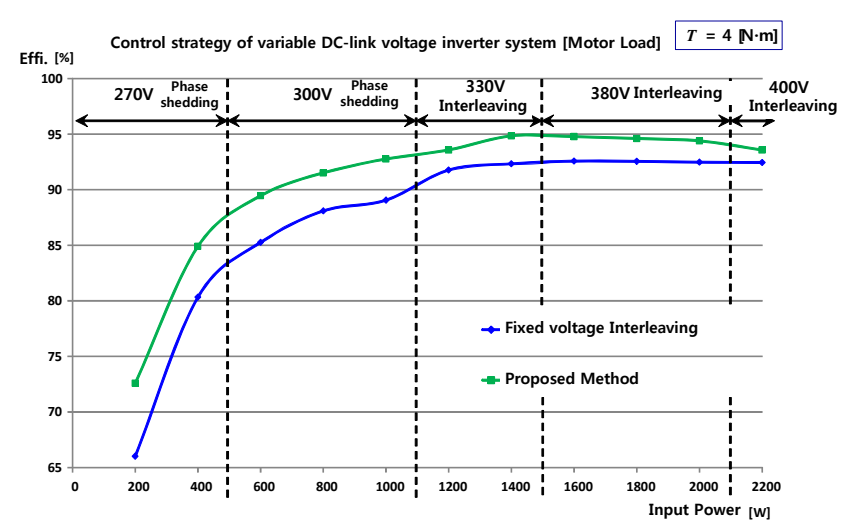

Fig. 12. Summarized control strategy of variable dc-link voltage inverter system.

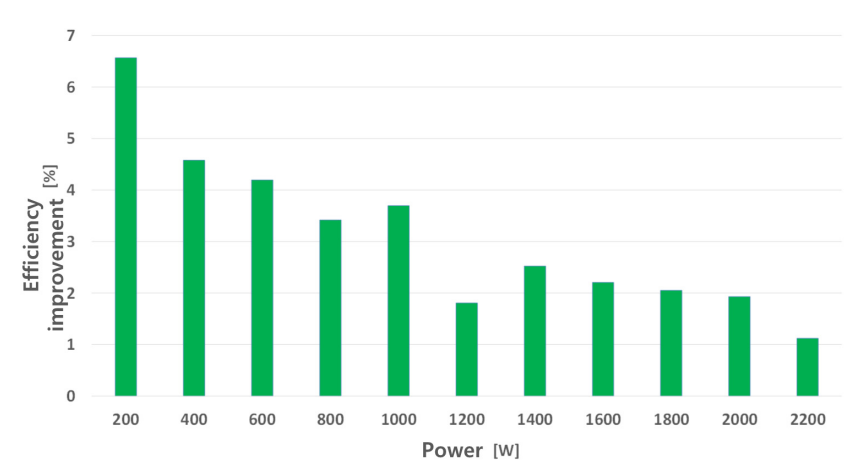

Fig. 13. Experimental system efficiency comparison between conventional system and proposed system.

example, noise and back-EMF. Therefore, total system efficiency is measured from the test-bed dynamo system. In case of compressor loads, torque variation is not changed widely. In this experiment, torque variation range is $1.9 \sim 5.6 \mathrm{Nm}$ and speed variation is 200 3000 RPM to satisfy cycle condition. Torque and speed have proportional relation. Output power has proportional relation in speed. In the test-bed dynamo system, fixed torque is used for simplification.

The optimal voltage to get the best system efficiency can be determined by Eq. (5) and the test-bed dynamo system. The optimal voltage has some sections for convenience. Fig. 12 shows these sections and strategy.

According to Fig. 12, there are five sections to determine the optimal control strategy from the input power range. For the range below $500 \mathrm{~W}$ (section 1), it is desirable to use phase shedding, $270 \mathrm{~V}$ dc control. For the range from 500 $\mathrm{W}$ to $1100 \mathrm{~W}$ (section 2), it is desirable to use phase 
shedding, $300 \mathrm{~V}$ dc control. For the range from $1100 \mathrm{~W}$ to $1500 \mathrm{~W}$ (section 3), it is desirable to use interleaving, 330 $\mathrm{V}$ dc control. For the range from $1500 \mathrm{~W}$ to $2100 \mathrm{~W}$ (section 4), it is desirable to use interleaving, $380 \mathrm{~V} \mathrm{dc}$ control. For the range over $2100 \mathrm{~W}$ (section 5), it is desirable to use interleaving, $400 \mathrm{~V}$ dc control. This strategy is summarized in Table 4.

Fig. 12 also shows the efficiency of the reference system and Fig. 13 shows the efficiency comparison results. A maximum $6.5 \%$ efficiency improvement can be achieved in light load condition. The efficiency improvement can be acquired regardless of load.

\section{Conclusion}

This paper proposes an efficiency improvement for variable dc-link voltage inverter systems and especially focuses on light load areas in home appliances. The validity of the proposed strategy has been verified by experimental results. Three methods are combined to achieve good efficiency of home appliances with a variable dc-link voltage inverter system.

A $2.2 \mathrm{KW}$ dynamo system is used to check the system efficiency. Finally, a maximum $6.5 \%$ efficiency improvement can be achieved using proposed system.

\section{Acknowledgements}

This work was supported by "Human Resources Program in Energy Technology" of the Korea Institute of Energy Technology Evaluation and Planning (KETEP), granted financial resource from the Ministry of Trade, Industry \& Energy, Republic of Korea. (No. 2016 4030200980)

\section{References}

[1] Liu, Xudan, et al. "A high-efficiency single-phase AC/DC converter with enabling window control and active input bridge." Power Electronics, IEEE Transactions on 27.6 (2012): 2912-2924.

[2] Lim, Shu Fan, and Ashwin M. Khambadkone. "Nonlinear inductor design for improving light load efficiency of boost PFC." Energy Conversion Congress and Exposition, 2009. ECCE 2009. IEEE. IEEE, 2009.

[3] Su, Jen-Ta, and Chih-Wen Liu. "A Novel PhaseShedding Control Scheme for Improved Light Load Efficiency of Multiphase Interleaved DC-DC Converters." IEEE transactions on power electronics 28.10 (2013): 4742-4752.

[4] Kwon, Young Ahn, and Sang Kyoon Kim. "A high-

performance strategy for sensorless induction motor drive using variable link voltage." Power Electronics, IEEE Transactions on 22.1 (2007): 329-332.

[5] IEC EN 61000-3-2 standard. http://en.wikipedia.org/wiki/IEC_EN_61000-3-2

[6] Sung Pil Ha, Jung Hyo Lee, Jung Pill Hwang, Jun Hyuk Choi, Chung Yuen Won. "Two Phase Interleaved Bidirectional DC-DC Converter for Electric Vehicle using Variable dc-Link Voltage." 2012 IEEE Vehicle Power and Propulsion Conference, Oct. 9-12, 2012, Seoul, Korea.

[7] Byung-Gu Kang, Chong-Eun Kim, Dong-Kwan Kim, Gun-Woo Moon. "Hirnlgh Power Density Cascade Buck-Boost PFC for High Input Voltage." KIPE Transactions on Power Electronics Annual Conference 2015.07, 247-248.

[8] M. C. Ghanem, K. Al-Haddad, and G. Roy, “A new control strategy to achieve sinusoidal line current in a cascade buck-boost converter," IEEE Trans. Ind. Electron., vol. 43, pp. 441-449, June 1996.

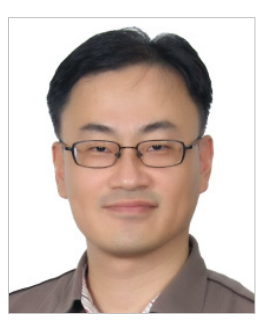

Hyun Soo Park He received the B.S. and M.S. degrees in electrical engineering from Yonsei University, Seoul, Korea, in 1993 and 1995, respectively. He is currently working toward the Ph.D. degree at Sungkyunkwan University, Suwon-si, Korea. In 1995, he joined the Digital Media and Communication R\&D Center, Samsung Electronics Company Ltd., Suwon, Korea, where he has developed large-scale integrators and algorithms. His current research topics are related to power electronics for home appliances.

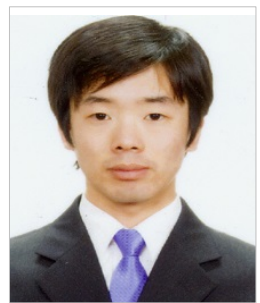

electric vehicles

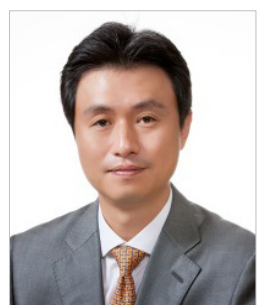

Minkook Kim He received the B.S degree in electrical engineering from Sungkyunkwan University, Suwon, Korea, in 2012, where he is currently working toward the combined M.S. and Ph.D. degree in electrical engineering. His research interest includes wireless power transfer system for

Byoung Kuk Lee He received the B.S. and the M.S. degrees from Hanyang University, Seoul, Korea, in 1994 and 1996, respectively and the Ph.D. degree from Texas A\&M University, College Station, TX, USA, in 2001, all in electrical engineering. From 2003 to 2005, he was a Senior Researcher 
with Power Electronics Group, Korea Electrotechnology Research Institute, Changwon, Korea. From 2006, he is with the College of Information and Communication Engineering, Sungkyunkwan University, Suwon, Korea. His research interests include on-board charger and wireless power transfer for electric vehicles, energy storage systems, hybrid renewable energy systems, dc distribution systems for home appliances, power conditioning systems for fuel cells and photovoltaic, modeling and simulation, and power electronics. Prof. Lee received the Outstanding Scientists of the 21st Century from IBC and listed on 2008 Ed. of Who's Who in America and 2009 Ed. of Who's Who in the World. He is an Associate Editor in the IEEE TRANSACTIONS ON INDUSTRIAL ELECTRONICS and Guest Associate Editor in the IEEE TRANSACTIONS ON POWER ELECTRONICS. He was the Presenter for Professional Education Seminar with the topic of "OnBoard Charger Technology for EVs and PHEVs" at the IEEE Applied Power Electronics Conference in 2014 and was the General Chair for the IEEE Vehicular Power and Propulsion Conference in 2012. 